Article

2

\title{
Development of a Food-based index of dietary inflammatory potential for Koreans and its relationship with metabolic syndrome
}

\author{
Woori Na ${ }^{1}$, Tae Yang $\mathbf{Y u}^{2, *}$, Cheongmin Sohn ${ }^{1, *}$ \\ ${ }^{1}$ Department of Food and Nutrition, Wonkwang University, Iksan, Republic of Korea \\ ${ }^{2}$ Division of Endocrinology and Metabolism, Department of Medicine, Wonkwang University School of \\ Medicine, Iksan, Republic of Korea \\ * Correspondence : ccha@wku.ac.kr(S.C); yutaeyang@gmail.com(Y.T.Y); Tel: +82-63-850-6656(S.C); +82-63-859- \\ 2670(Y.T.Y) \\ * Tae Yang Yu and Cheongmin Sohn contributed equally to this work.
}

\begin{abstract}
Inflammation is known to be risk factors for metabolic diseases. The purpose of this study was to develop a Food-based Index of Dietary Inflammatory Potential (FBDI) and conduct its validation assessment. This study analyzed raw data from Korean Genome and Epidemiology Study 2012-2014 data of 17,771 people. We carried out the correlation analysis between 51 food groups and hs-CRP. The FBDI was developed by multiple regression method with hs-CRP and selected 17 food group. For the validation of FBDI, 7,795 people in the 6th Korea National Health and Nutrition Examination Survey (KNHAES) was used. Binary logistic regression analysis was used for risk analysis of metabolic syndrome and FBDI. The FBDI model included that 7 were composed of antiinflammatory food groups and 3 of inflammatory food groups. The FBDI was calculated by multiplying the intake of food group by $\beta$ coefficients. KNHAES were included in the validation of FBDI. The risk of metabolic syndrome was found to be 2.152 times higher in the group with the highest FBDI than in the group with the lowest one ( $95 \% \mathrm{Cl}: 1.458-3.178$, $\mathrm{p}$ for trend $=0.000)$. This study developed FBDI reflecting food intake for Koreans, which showed a significant relationship with the risk of metabolic syndrome.
\end{abstract}

Keywords: metabolic syndrome; inflammation; index; Korea

\section{Introduction}

Current trends in metabolic diseases such as obesity, diabetes, hypertension, hyperlipidemia and cerebrovascular disease, which are highly related to lifestyle, show an overall increase in prevalence. This leads to an increase in domestic and overseas medical expenses; thus, preventive management is emphasized. The lack of physical activity, diet-related factors[1-6] and chronic inflammation have been reported as major factors related to metabolic diseases. Chronic inflammation has been reported to affect both the expression and progression of metabolic diseases and high sensitivity C-reactive protein (hs-CRP), nuclear factor kappa B (NF-kB), interleukin-6 (IL-6), and tumor necrosis factor $\alpha$ $(\mathrm{TNF}-\alpha)$ are known as typical inflammatory indexes. The American Heart Association and the Centers for Disease Control and Prevention (AHA/CDCP) have proposed the use of hs-CRP as a risk assessment index for patients with cardiovascular disease.[7]

Several studies have reported that chronic inflammation is also highly associated with dietary factors. The relationship between inflammation and nutrients such as vitamins, complex carbohydrates, and dietary fiber, has been reported[8-12] and food groups such as vegetables and fruits,[13] and whole grains[14] have been found to lower inflammation. Dietary patterns, as well as 
single nutrients and foods, have been reported to be associated with chronic inflammation, and the Mediterranean diet has been reported to be a typical anti-inflammatory diet.[15] On the other hand, Western dietary patterns that involve the consumption of high-fat red meat, high-fat dairy products, and refined grains, are reported to cause chronic inflammation.[16]

Thus, Shivappa et al. developed a non-invasive method of estimating inflammation associated with meal intake using systematic literature review data.[17] The results of studying U.S. and Europe centered dietary inflammatory index (DII) showed that the increase in DII correlates with the risk of asthma, depression, various cancers, and the risk of mortality from cancer,[18] and also correlates with the risk of metabolic syndrome[19] or cerebrovascular disease,[20-22] which are representative metabolic diseases. The variables used in the formula for DII are the nutrient analysis value and food intake, requiring analysis and calculation steps after the dietary intake survey. Therefore, it cannot be used readily in the clinical nutrition field. In addition, Tabung et al. developed the empirical dietary inflammatory index (EDII) based on food intake,[23] but its application to Koreans with different eating patterns is limited because it mainly reflects foods consumed in Western diets. The purpose of this study was to develop the food-based Index of dietary inflammatory potential (FBDI) model as food units, reflecting dietary pattern for Korean and estimating inflammation through intake analysis in an actual clinical nutrition field. In order to assess the validity of the FBDI tool, the relationship between the risk of metabolic syndrome and FBDI was analyzed using data from the Korea National Health and Nutrition Examination Survey (KNHENES).

\section{Materials and Methods}

\subsection{Development of the FBDI assessment tool}

\subsubsection{Food groups}

For the development of the FBDI, data from the Korean Genome and Epidemiology Study (KoGES)-Health Examinee (HEXA) were used and classified into 51 food groups. Grain were classified into nine categoris white rice, other grains, bread and wheat flour, noodles, ramen, pizza and hamburgers, rice cake, cereal, and sweets. Based on data from International Agency for Research on Cancer (IARC), fruits were divided into similar colors and classified into four kinds of orange fruit, citrus, red fruit, and berries[24] Vegetables were divided according to colors or characteristics and classified into six kinds of green vegetables, cabbage and stem vegetables, lettuce, onion, bulbs, red vegetables and tomatoes, kimchi, ginger, and ginseng. Kimchi, frequently consumed by Koreans, was categorized separately. Meat was classified based on the criteria reported in a study conducted by Linseisen et al.[25] and was finally divided into eight categories: beef, pork, bacon, poultry, intestines, other meat, processed meat product, and fried chicken. Beverages were classified into four kinds, including bean and leaf tea, sikhye and carbonated beverage, mixed coffee and sweetened drinks, and alcohol; seafood into four kinds such as fish, shellfish, processed seafood, salted seafood and fish eggs; and fat and oils into animal fats and vegetable oils. In addition, the food groups were classified into 51 foods: potato and starch, sugars, legumes, nuts and seeds, mushrooms, eggs, seaweed, dairy products, seasoning, processed foods and others.

Table 1. Food groups classification

\begin{tabular}{ccc}
\hline Food group & $\begin{array}{c}\text { Reclassified } \\
\text { food }\end{array}$ & Reclassified food group \\
\hline Cereals & 9 & $\begin{array}{c}\text { white rice, other grain, Bread·Wheat flour, noodles, ramen, } \\
\text { pizza.hamburgers·sandwiches, rice cake, cereal, and sweets }\end{array}$ \\
$\begin{array}{c}\text { Potato and } \\
\text { starch }\end{array}$ & 1 & - \\
Sugars & 1 & - \\
Legumes & 1 & -
\end{tabular}




\begin{tabular}{|c|c|c|}
\hline Nuts and seeds & 1 & - \\
\hline Vegetables & 9 & $\begin{array}{c}\text { green vegetables, cabbage and stem vegetables, lettuce, onion, } \\
\text { bulbs, red vegetables and tomatoes, kimchi, ginger, and } \\
\text { ginseng }\end{array}$ \\
\hline Mushrooms & 1 & - \\
\hline Fruit & 4 & orange fruit, citrus, red fruit, berries \\
\hline Meat & 8 & $\begin{array}{l}\text { beef, pork, bacon, poultry, intestines, the other meat, processed } \\
\text { meat product, and fried chicken }\end{array}$ \\
\hline Eggs & 1 & - \\
\hline Seafood & 4 & fish, shellfish, processed seafood, salted seafood, and fish eggs \\
\hline Seaweed & 1 & - \\
\hline Dairy products & 1 & - \\
\hline Fat and oils & 2 & animal fat, vegetable oils \\
\hline $\begin{array}{l}\text { Beverages and } \\
\text { Alcohol }\end{array}$ & 4 & $\begin{array}{c}\text { bean and leaf tea, sikhye and carbonated beverage, mixed } \\
\text { coffee and sweetened drinks, alcohol }\end{array}$ \\
\hline Seasoning & 1 & - \\
\hline $\begin{array}{l}\text { Processed } \\
\text { foods }\end{array}$ & 1 & - \\
\hline Etc. & 1 & - \\
\hline 18 & 51 & \\
\hline
\end{tabular}

\subsubsection{Selection of subjects}

The 24-hour recall method data of males and females aged 40-72 years who participated in the 2012-2014 KoGES HEXA was utilized. We excluded subjects with hs-CRP values of more than 10 $\mathrm{mg} / \mathrm{L}$. Also, after excluding those diagnosed with hypertension, diabetes, stroke, myocardial infarction, angina pectoris, chronic gastritis, gastric ulcer, duodenal ulcer, chronic hepatitis, cholecystitis, bronchitis, arthritis, and cancer, which could potentially affect hs-CRP levels, 17,771 subjects were included in the final analysis. The present study was approved by the Clinical Test Deliberation Commission of the Institutional Review Board, Wonkwang University (WKIRB-201801SB-006).

\subsubsection{Statistical analysis}

Spearman correlation analysis between log hs-CRP and the 51 food groups was carried out to select food groups with significant correlation. The selected 17 food groups were analyzed using the stepwise selection method of multiple regression with hs-CRP and the formula for FBDI was developed using the regression coefficients derived from the regression equation. All statistical analyses were performed with SPSS version 23.0 (IBM Corp., Armonk, NY, USA).

\subsection{Validation of the FBDI}

\subsubsection{Selection of subjects}

The validity of the FBDI was analyzed for 13,525 adults aged 20-64 in the 6th KNHANES (20132015). A total of 7,795 people were selected for the study, after excluding those with missing data $(n=2,277)$, no 24-hour recall data $(n=4,751)$, and who did dietary therapy $(n=3,947)$. Metabolic syndrome was diagnosed according to the definition of the Modified National Cholesterol Education Program Adult Treatment Panel III (NCEP-ATP III) proposed by the American Heart Association and National Heart, Lung, and Blood Institute (AHA/NHLBI) in 2005. HDL-cholesterol concentration of $\leq 40 \mathrm{mg} / \mathrm{dL}$ in men and $\leq 50 \mathrm{mg} / \mathrm{dL}$ in women, triglycerides $\geq 150 \mathrm{mg} / \mathrm{dL}$, systolic blood pressure 
$\geq 130 \mathrm{mmHg}$ or diastolic blood $\geq 85 \mathrm{mmHg}$, or fasting blood glucose $\geq 100 \mathrm{mg} / \mathrm{dL}$ were diagnosed as metabolic syndrome. Regarding waist circumference, the Obesity Treatment Guidelines of the Korean Society for the Study of Obesity were applied. Cut-off values of $90 \mathrm{~cm}$ and $85 \mathrm{~cm}$ were considered for men and women, respectively, beyond which the individual was diagnosed with metabolic syndrome.[26] Demographic variables such as age, gender, household income, and education level of the subjects were surveyed through questionnaires, and body mass index was calculated from the values obtained for height and weight.

\subsubsection{Statistical analysis}

In order to evaluate the difference in general body measurements, biochemical indicators and nutrient intake according to FBDI, FBDI values were divided into quartiles and ANOVA and crossover analyses were performed. In addition, odds ratio (OR) and confidence interval (CI) were calculated by performing binary logistic regression analysis to analyze the risk of metabolic syndrome with increasing FBDI. All analyses were performed as composite sample analyses, and household income, education level, present smoking status (current/past/non-smoker), and moderate physical activity practice rate $(\mathrm{Y} / \mathrm{N})$ were used as nominal correction variables, and age, energy intake and body mass index as continuous correction variables. All statistical analyses were performed using SPSS version 23.0 (IBM Corp., Armonk, NY, USA).

\section{Results}

\subsection{Development of FBDI assessment tool model}

The final formula model of FBDI is shown in Figure 1. After repeating the multiple regression analysis for seventeen food groups identified as being correlated through the nonparametric correlation analysis between 51 food groups and hs-CRP, we developed the formula using the beta $(\beta)$ coefficients of the multiple regression equation for the 10 food groups for which significance was confirmed. At this time the $\beta$ coefficients derived from each food group was too small, so there was some difficulty in the analysis for actual use. Therefore, each $\beta$ coefficient was multiplied by 100.

\subsection{Validation of FBDI}

\subsubsection{Correlation analysis between FBDI and Health indicators}

Table 2 shows the results of the analysis of the characteristics of subject correlation according to FBDI using the 6th KNHANES data for the validation of FBDI. There was significant difference in sex, income, education level and energy intake (kcal) with increasing FBDI, but no significant difference with age, BMI, smoking status and experience of physical activity.

Table 2. Characteristics of subjects according to FBDI

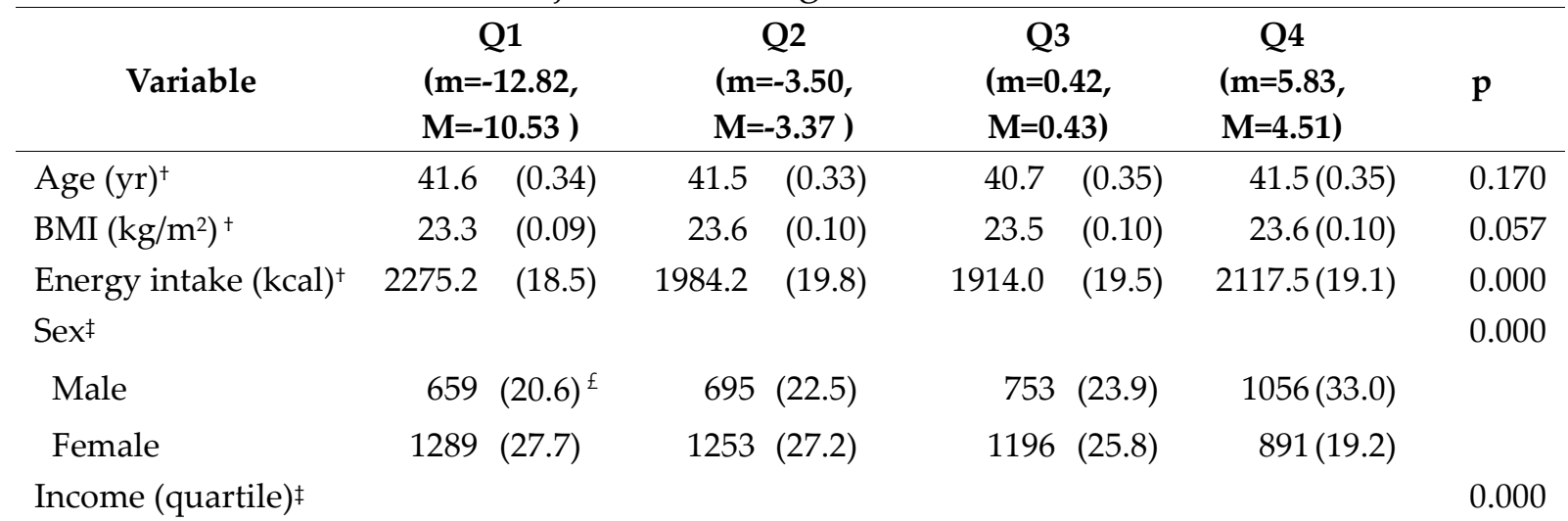




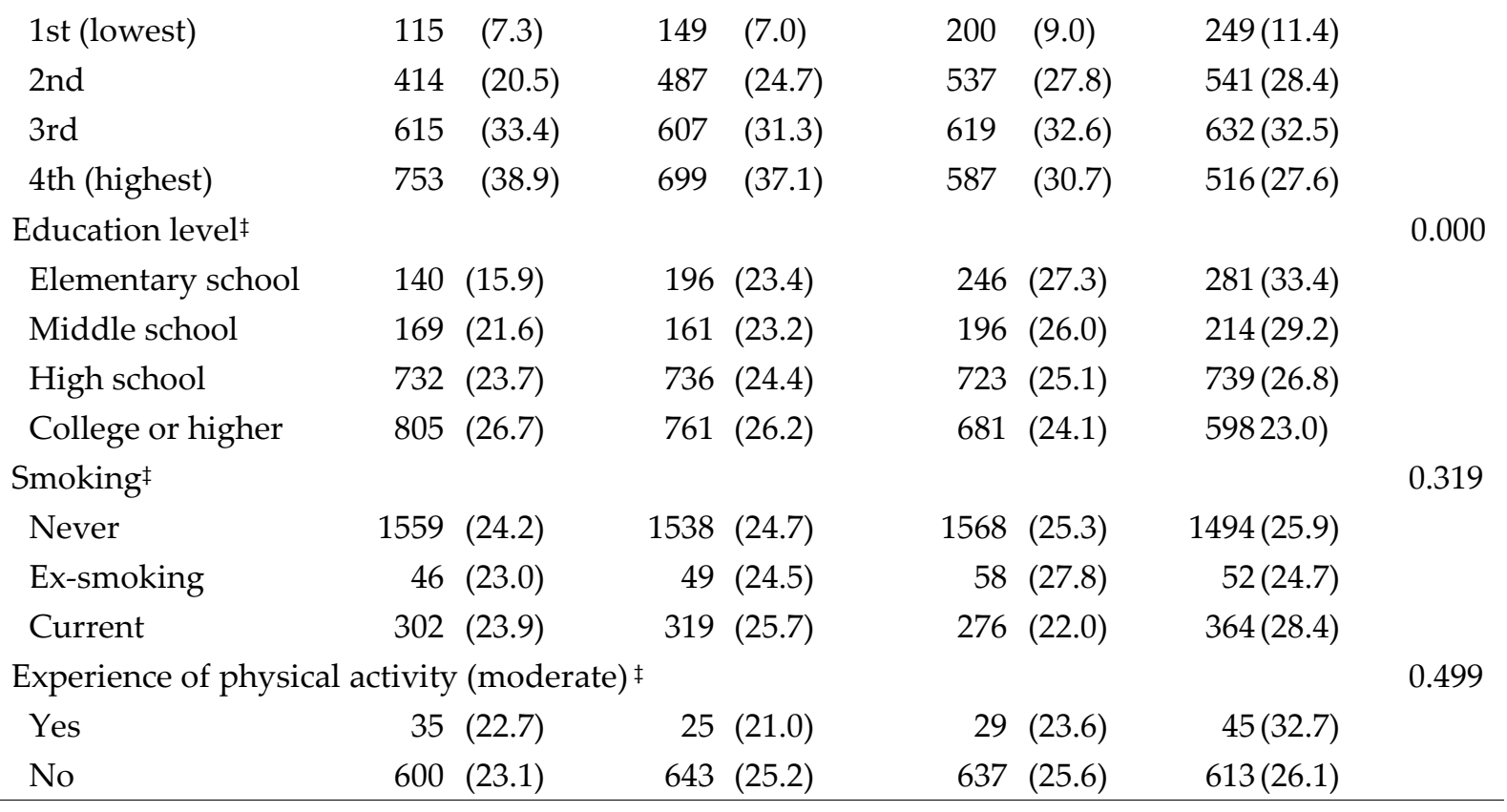

FBDI quartile range: Q1: -79.16 -6.10, Q2: -6.10 -1.29, Q3: -1.29 2.20, Q4: 2.20 39.02 $(\mathrm{m}=\mathrm{mean}, \mathrm{M}=$ median). ${ }^{\dagger}$ Mean (SD); $\neq$ n (\%)

160

161

162

163

164

165

166

3.2.2. Comparison of metabolic syndrome indicators and blood lipid concentration according to FBDI

Table 3 shows the comparison of metabolic syndrome indicators and blood lipid concentration according to FBDI. Systolic blood pressure, fasting blood glucose, and triglyceride, which are components of metabolic syndrome, were found to significantly increase with increasing FBDI, and HDL-cholesterol was found to significantly decrease with increasing FBDI.

Table 3. Comparison of metabolic syndrome indicator and blood lipid concentration according to FBDI

\begin{tabular}{|c|c|c|c|c|c|c|c|c|}
\hline \multirow{2}{*}{$\begin{array}{c}\text { Variable } \\
\text { Exposure of MS, n(\%) }\end{array}$} & \multicolumn{2}{|c|}{$\begin{array}{c}Q 1 \\
(\mathrm{~m}=-12.82 \\
M=-10.53)\end{array}$} & \multicolumn{2}{|c|}{$\begin{array}{c}\mathrm{Q} 2 \\
(\mathrm{~m}=-3.50, \\
\mathrm{M}=-3.37)\end{array}$} & \multicolumn{2}{|c|}{$\begin{array}{c}\text { Q3 } \\
(\mathrm{m}=0.42 \\
\mathrm{M}=0.43)\end{array}$} & \multirow{2}{*}{$\begin{array}{c}\begin{array}{c}\mathrm{Q} 4 \\
(\mathrm{~m}=5.83 \\
\mathrm{M}=4.51)\end{array} \\
548(32.3)\end{array}$} & \multirow{2}{*}{$\begin{array}{c}\mathbf{p} \\
0.000\end{array}$} \\
\hline & 334 & (19.1) & 424 & $(25.1)$ & 405 & $(23.6)$ & & \\
\hline \multicolumn{9}{|l|}{ MS component } \\
\hline $\mathrm{WC}(\mathrm{cm})$ & 79.3 & $(0.28)$ & 80.3 & $(0.28)$ & 80.1 & $(0.29)$ & $81.4(0.27)$ & 0.000 \\
\hline SBP (mmHg) & 112.9 & $(0.37)$ & 113.8 & $(0.38)$ & 114.0 & $(0.40)$ & $115.9(0.41)$ & 0.000 \\
\hline DBP (mmHg) & 74.7 & $(0.28)$ & 75.2 & $(0.29)$ & 75.1 & $(0.30)$ & $76.7(0.28)$ & 0.000 \\
\hline $\begin{array}{l}\text { Fasting glucose } \\
(\mathrm{mg} / \mathrm{dl})\end{array}$ & 96.7 & $(0.60)$ & 97.0 & $(0.54)$ & 96.8 & $(0.61)$ & $98.5(0.56)$ & 0.066 \\
\hline TG (mg/dl) & 133.0 & $(4.58)$ & 135.0 & $(3.08)$ & 135.5 & $(2.96)$ & $152.4(3.53)$ & 0.000 \\
\hline HDL-chol (mg/dl) & 52.4 & $(0.33)$ & 51.8 & $(0.31)$ & 52.1 & $(0.34)$ & $50.1(0.32)$ & 0.000 \\
\hline \multicolumn{9}{|c|}{ Other blood lipid concentrations } \\
\hline $\begin{array}{l}\text { Total } \quad \text { cholesterol } \\
(\mathrm{mg} / \mathrm{dl})\end{array}$ & 188.9 & $(0.95)$ & 189.0 & $(0.95)$ & 188.2 & $(0.96)$ & $188.6(0.98)$ & 0.901 \\
\hline LDL-chol (mg/dl) & 113.8 & $(1.32)$ & 115.0 & $(1.28)$ & 116.6 & $(1.29)$ & $114.6(1.27)$ & 0.439 \\
\hline
\end{tabular}

WC: Waist Circumference

SBP: Systolic Blood Pressure

DBP: Diastolic Blood Pressure

TG: Triglyceride 
HDL-chol: High-density lipoprotein cholesterol

LDL-chol:Low-density lipoprotein cholesterol

167

168

169

170

171

172

173

174

175

\subsubsection{Risk analysis of metabolic syndrome according to FBDI}

Table 4 shows the results of the binary logistic regression analysis for the risk analysis of metabolic syndrome with increasing FBDI. Among all subjects, age, sex, education level, income level, BMI, caloric intake, smoking, physical activity, were corrected and as a result, the risk of metabolic syndrome was found to be 2.152 times higher in the group with highest FBDI than in the group with lowest FBDI (95\% Cl: 1.458-3.178) $(\mathrm{p}=0.002$, $\mathrm{p}$ for trend $=0.000)$.

Table 4. Odd ratios of metabolic syndrome according to FBDI

\begin{tabular}{|c|c|c|c|c|c|c|c|c|}
\hline \multirow{2}{*}{$\begin{array}{l}\text { Variable } \\
\text { Crude }\end{array}$} & \multirow{2}{*}{$\begin{array}{c}\text { Q1 } \\
1 \\
(\mathrm{ref})\end{array}$} & \multicolumn{2}{|c|}{$\begin{array}{c}\mathrm{Q} 2 \\
\text { OR }(95 \% \mathrm{CI}) \\
\end{array}$} & \multicolumn{2}{|c|}{$\begin{array}{c}\mathrm{Q3} \\
\text { OR }(95 \% \mathrm{CI}) \\
\end{array}$} & \multirow{2}{*}{$\begin{array}{c}\text { Q4 } \\
\text { OR }(95 \% \text { CI }) \\
1.768(1.489-2.100)\end{array}$} & \multirow{2}{*}{$\begin{array}{l}\mathbf{p} \\
0.000\end{array}$} & \multirow{2}{*}{$\begin{array}{l}\mathbf{p} \text { for } \\
\text { trend }\end{array}$} \\
\hline & & 1.352 & $(1.126-1.622)$ & 1.250 & $(1.037-1.506)$ & & & \\
\hline Adjusted model $1^{+}$ & 1 & 1.378 & $(1.126-1.686)$ & 1.285 & $(1.052-1.570)$ & $1.449(1.202-1.748)$ & 0.001 & 0.001 \\
\hline Adjusted model $2 \ddagger$ & 1 & 1.374 & $(1.116-1.692)$ & 1.256 & $(1.015-1.552)$ & $1.397(1.147-1.702)$ & 0.004 & 0.006 \\
\hline Adjusted model 3\$, & 1 & 1.405 & $(1.110-1.780)$ & 1.340 & $(1.046-1.716)$ & $1.675(1.345-2.088)$ & 0.000 & 0.000 \\
\hline Adjusted model 4I, & 1 & 1.379 & $(0.946-2.010)$ & 1.384 & $(0.954-2.007)$ & $2.152(1.458-3.178)$ & 0.002 & 0.000 \\
\hline
\end{tabular}

176

177

${ }^{+}$Adjusted model 1 : adjusted for sex, and age

$\ddagger$ Adjusted model 2 : adjusted for sex, age, education, and income

$\S$ Adjusted model 3 : adjusted for sex, age, education, income, BMI, and energy

IIAdjusted model 4 : adjusted for sex, age, education, income, BMI, energy, smoking, and physical activity

\section{Discussion}

The purpose of this study is to develop an FBDI reflecting the actual inflammatory index and dietary intake of the Korean people and to conduct a validity analysis.

Among FBDI composition food groups selected through this study, those which showed negative correlation with inflammation were found to be green vegetables, eggs, citrus, legumes, red fruits, Bread-Wheat flour, nuts and seeds and the food groups showing positive correlation were found to be 10 in total, and included mixed coffee, sweetened drinks, white rice and beef. Previous studies on the relationship between food groups and chronic inflammation showed that there were many specific foods such as whole grains, fruits, vegetables, brewed coffee and tea, the intake of which decreases CRP level.[27,28] The relationship between hs-CRP and food group derived from this study showed that as the intake of nuts, legumes and apples increases, hs-CRP decreases,[28-31] and the increase in intake of citrus polyphenol, which is abundant in citrus and flavonoid that is abundant in red fruit decreases the blood levels of hs-CRP.[28,32] However, white rice,[33] mixed coffee, beef, bread, Bread and Wheat flour, and eggs showed no significant difference in variation of hs-CRP, or rather the opposite result in this study. The first reason for this result is that the analysis conducted in this study closely reflects the food intake characteristics of Koreans. For example, it has been reported that the increase in coffee intake tends to lower hs-CRP,[34] but Koreans consume a significant amount of mixed coffee.[35] Thus, this study classified and analyzed mixed coffee and brewed coffee and as a result, they were found to be food groups showing positive correlation with hs-CRP. Another reason for the selection of food groups is that recent studies on the relationship between food groups and health indicators were not limited to one food group but analyzed the relevance of interactions between food groups. For this reason, 10 food groups were selected in this study using multiple regression analysis, which considers the effect between food groups on the selection of final food groups. The EDII also includes tomatoes, other vegetables, other fish in the food group showing positive correlation with inflammation, beer, wine, snack, pizza in the food group showing negative correlation,[23] indicating that food intake patterns seem to have a 
significant impact on inflammation rather than the effects of one food group. The method of selecting food groups by the interaction between food groups utilized in the analytical method of this study derived meaningful results by the analytical method. For example, white rice and beef, which are found to increase inflammation in this study, can be said to be foods with high nutritional values when considered alone. In the traditional Korean diet, it is possible to eat various nutrients in a balanced way through rice, soup, and various side dishes. As a result, ordinary Korean people perceive Korean food that is consumed with rice as healthy diet.[36] However, it has been reported that Koreans actually consume relatively high amounts of carbohydrates by ingesting rice, soup or stew, one or two side dishes, which is closely related to the increase in metabolic syndrome, diabetes, and dyslipidemia. $[37,38]$ As shown above, the relationship between the unbalanced dietary intake of foods consumed by Koreans and chronic disease can be used as a sufficient basis to explain the food groups derived in this study. In light of the results of this study, studies on food intake patterns need to be carried out to reflecting the characteristics by region and age. Therefore, based on the results of this study, it is necessary to analyze the close relationship between food intake pattern and inflammation for each analysis subject in the future research. In addition, when suggesting guidelines and educational materials for metabolic disease patients with contents related to food groups derived through FBDI, it should be structured to involve the consumption of foods that are derived or restricted, rather than emphasizing one food.

The FBDI developed in this study has several specificity. The FBDI was developed to reflect the relationship between inflammation and dietary intake using the analysis results of actual subjects. Another significance is that it was developed with a focus on utilization in clinical nutrition practice from the point of designing the index. FBDI has the advantage in that the calculation can be simplified by applying only the total intake of the 10 food groups extracted from the subjects to the formula. In addition, the EDII, which was developed as an index reflecting the relevance of dietary intake with IL-6, CRP, TNF $\alpha$ receptor 2, and adiponectin through data such as Nurses Health Study (NHS), Nurses Health Study (NHS- II) and Health Professionals' Follow-up Study (HPFS), is similar to this study in terms of utilizing the actual inflammatory index,[23] but it shows differences in the types of inflammation-related foods by conducting the analysis for Koreans with different eating patterns. The finally developed FBDI is considered to be an index that can measure the level of inflammation through meals in countries with rice as a staple food. In addition, FBDI can be calculated only by the intake of the food group, so it is expected that the inflammation level can be predicted by a simple meal survey in the clinical nutrition setting.

In a previous study, the researchers developed the inflammatory index that based dietary for Korean (K-DII) by selecting the final 17 food groups through logistic regression analysis after propensity score matching with those with hs-CRP values of $3 \mathrm{mg} / \mathrm{L}$ or higher in the same group in the ratio of 1:2.[39] However, the study developed the index for metabolic disease patients by extracting only subjects whose hs-CRP were matched at values higher than $3 \mathrm{mg} / \mathrm{L}$. Given that hsCRP is reported as a management and prediction index of cerebrovascular disease, FBDI reflecting the dietary intake of healthy people can be used by anyone, so it seems to be able to exert a more effective value than the K-DII developed in the previous study. Currently, hs-CRP is known as an inflammatory index that can determine the individual's health status and the AHA/CDCP present the criteria for hs-CRP as an index for treatment and prognostic monitoring of patients with cardiovascular disease[7,40]. Recently, the usefulness of hs-CRP as a predictor of cardiovascular disease has been verified through various studies. Considering the incidence of cerebrovascular disease and its mortality rate among Koreans, and the subjects used in the development of this study, the FBDI developed by applying hs-CRP is considered to show a sufficient utilization value for prevention and management of cerebrovascular disease by estimating inflammation through meals. For the validation of the FBDI, this study analyzed the 6th National Health and Nutrition Examination Survey data. Lower FBDI scores imply an anti-inflammatory diet and higher scores reflect inflammatory meals. As a result of the analysis of the relationship between FBDI divided into quartiles and metabolic syndrome, as FBDI increases, waist circumference, systolic blood pressure, diastolic blood pressure, triglycerides, and HDL-cholesterol were significantly different among the 
components of metabolic syndrome and the risk of metabolic syndrome was also different. Metabolic syndrome is a disease that has been reported to correlate with various forms of inflammation, and many studies have shown the relationship with hs-CRP. A study by showed a positive correlation between CRP and triglyceride[41], and another study for 229 adults with metabolic syndrome in Korea showed a positive correlation between hs-CRP and waist circumference.[42] In a study by Ridker et al. the number of constituents of metabolic syndrome was significantly increased according to the concentration of CRP[43], and in the study conducted by Santos et al. for adults in the Portuguese region, all five components of the metabolic syndrome were significantly higher in CRP when the criteria for metabolic syndrome are met and as the number of constituent indicators increased, the average concentration of CRP increased.[44] In this study, the risk of metabolic syndrome was increased in the group with higher FBDI than in the group with lowest FBDI. The study conducted by Indulekha et al. of Asian-Indians showed that as the log hs-CRP value increases, the risk of metabolic syndrome increases[45], and $\mathrm{Vu}$ et al. reported that increased incidence of metabolic syndrome, diabetes, past CVD, and CRP are associated with the risk of peripheral vascular disease.[46] In the study by Danesh et al. that analyzed the Reykjavik study, the risk of coronary artery disease was found to be 1.92 times higher in patients over CRP $2 \mathrm{mg} / \mathrm{L}$, showing that CRP is closely related to vascular disease prognosis.[40] The relationship between FBDI and the metabolic syndrome was confirmed by previous studies such as the pattern of hs-CRP concentration in the metabolic syndrome, the risk of metabolic syndrome according to hs-CRP concentration, and the risk of cardiovascular disease. In this study, the validation of FBDI was carried out for one disease, called metabolic syndrome, but since the metabolic syndrome includes reference indicators such as blood glucose, triglycerides, blood pressure, and waist circumference, it is necessary to validate various cardiovascular diseases to utilize FBDI in clinical nutrition field. The limitation of this study is the analysis of FBDI using the 24-hour recall method during the development and analysis of FBDI, which may not reflect a usual intake pattern. In addition, FBDI was developed by analyzing the relevance between actual inflammatory index and food intake, but it was developed using only hsCRP, a typical inflammatory index. However, this study is significant in that it developed nutritional assessment tool that can be easily used on the clinical site reflecting the dietary inflammatory potential of Korean.

Acknowledgments: This work was supported by the National Research Foundation of Korea (NRF) grant funded by the Korea Government (MSIP) (No.NRF-2016R1A2B1014466)

Author Contributions: C.S. and Y.T.Y. conceived and designed the study; Y.T.Y and N.W. analyzed the data; C.S. and N.W wrote the paper.

Conflicts of Interest: No potential conflicts of interest were disclosed. 


\section{References}

1. Zhu, S.; St-Onge, M.-P.; Heshka, S.; Heymsfield, S.B. Lifestyle behaviors associated with lower risk of having the metabolic syndrome. Metabolism 2004, 53, 1503-1511. https://doi.org/10.1016/j.metabol.2004.04.017.

2. Hoffmann, I.S.; Cubeddu, L.X. Salt and the metabolic syndrome. Nutr Metab Cardiovasc Dis 2009, 19, 123-128. https://doi.org/10.1016/j.numecd.2008.02.011.

3. Czernichow, S.; Vergnaud, A.-C.; Galan, P.; Arnaud, J.; Favier, A.; Faure, H.; Huxley, R.; Hercberg, Ahluwalia, N. Effects of long-term antioxidant supplementation and association of serum antioxidant concentrations with risk of metabolic syndrome in adults. Am I Clin Nutr 2009, 90, 329-335. https://doi.org/10.3945/ajen.2009.27635.

4. Ebrahimi, M.; Ghayour-Mobarhan, M.; Rezaiean, S.; Hoseini, M.; Parizade, S.M.R.; Farhoudi, F.; Hosseininezhad, S.J.; Tavallaei, S.; Vejdani, A.; Azimi-Nezhad, M. Omega-3 fatty acid supplements improve the cardiovascular risk profile of subjects with metabolic syndrome, including markers of inflammation and auto-immunity. Acta cardiologica 2009, 64, 321-327. 10.2143/AC.64.3.2038016.

5. Yoo, K.-B.; Suh, H.-J.; Lee, M.-J.; Kim, J.-H.; Kwon, J.A.; Park, E.-C. Breakfast eating patterns and the metabolic syndrome: The korea national health and nutrition examination survey (knhanes) 2007-2009. Asia Pac J Clin Nutr 2013. 10.6133/apjen.2014.23.1.08

6. Alkerwi, A.a.; Boutsen, M.; Vaillant, M.; Barre, J.; Lair, M.-L.; Albert, A.; Guillaume, M.; Dramaix, M. Alcohol consumption and the prevalence of metabolic syndrome: A metaanalysis of observational studies. Atherosclerosis 2009, 204, 624-635. 10.1016/j.atherosclerosis.2008.10.036

7. Pearson, T.A.; Mensah, G.A.; Alexander, R.W.; Anderson, J.L.; Cannon, R.O., 3rd; Criqui, M.; Fadl, Y.Y.; Fortmann, S.P.; Hong, Y.; Myers, G.L., et al. Markers of inflammation and cardiovascular disease: Application to clinical and public health practice: A statement for healthcare professionals from the centers for disease control and prevention and the american heart association. Circulation 2003, 107, 499-511. https://doi.org/10.1161/01.CIR.0000052939.59093.45

8. Kitabchi, A.E.; McDaniel, K.A.; Wan, J.Y.; Tylavsky, F.A.; Jacovino, C.A.; Sands, C.W.; Nyenwe, E.A.; Stentz, F.B. Effects of high-protein versus high-carbohydrate diets on markers of $\beta$-cell function, oxidative stress, lipid peroxidation, proinflammatory cytokines, and adipokines in obese, premenopausal women without diabetes: A randomized controlled trial. Diabetes Care 2013, 36, 1919-1925. https://doi.org/10.2337/dc12-1912

9. Ferrucci, L.; Cherubini, A.; Bandinelli, S.; Bartali, B.; Corsi, A.; Lauretani, F.; Martin, A.; Andres-Lacueva, C.; Senin, U.; Guralnik, J.M. Relationship of plasma polyunsaturated fatty acids to circulating inflammatory markers. J Clin Endocrinol Metab 2006, 91, 439-446. https://doi.org/10.1210/jc.2005-1303

10. Ma, Y.; Griffith, J.A.; Chasan-Taber, L.; Olendzki, B.C.; Jackson, E.; Stanek, E.J., 3rd; Li, W.; Pagoto, S.L.; Hafner, A.R.; Ockene, I.S. Association between dietary fiber and serum c-reactive protein. Am J Clin Nutr 2006, 83, 760-766. https://doi.org/10.1093/ajcn/83.4.760

11. Bertran, N.; Camps, J.; Fernandez-Ballart, J.; Arija, V.; Ferre, N.; Tous, M.; Simo, D.; Murphy, M.M.; Vilella, E.; Joven, J. Diet and lifestyle are associated with serum c-reactive protein concentrations in a population-based study. J Lab Clin Med 2005, 145, 41-46. https://doi.org/10.1016/j.lab.2004.11.002.

12. Wannamethee, S.G.; Lowe, G.D.; Rumley, A.; Bruckdorfer, K.R.; Whincup, P.H. Associations of vitamin c status, fruit and vegetable intakes, and markers of inflammation and hemostasis. Am J Clin Nutr 2006, 83, 567-574; quiz 726-567. https://doi.org/10.1093/ajcn.83.3.567

13. Esmaillzadeh, A.; Kimiagar, M.; Mehrabi, Y.; Azadbakht, L.; Hu, F.B.; Willett, W.C. Fruit and vegetable intakes, c-reactive protein, and the metabolic syndrome. Am J Clin Nutr 2006, 84, 1489-1497. https://doi.org/10.1093/ajcn/84.6.1489

14. Lutsey, P.L.; Jacobs, D.R.; Kori, S.; Mayer-Davis, E.; Shea, S.; Steffen, L.M.; Szklo, M.; Tracy, R. Whole grain intake and its cross-sectional association with obesity, insulin resistance, 
inflammation, diabetes and subclinical cvd: The mesa study. Br J Nutr 2007, 98, 397-405. https://doi.org/10.1017/S0007114507700715

15. Esposito, K.; Marfella, R.; Ciotola, M.; Di Palo, C.; Giugliano, F.; Giugliano, G.; D'Armiento, M.; D'Andrea, F.; Giugliano, D. Effect of a mediterranean-style diet on endothelial dysfunction and markers of vascular inflammation in the metabolic syndrome: A randomized trial. Jama 2004, 292, 1440-1446. 10.1001/jama.292.12.1440

16. Johansson-Persson, A.; Ulmius, M.; Cloetens, L.; Karhu, T.; Herzig, K.H.; Onning, G. A high intake of dietary fiber influences c-reactive protein and fibrinogen, but not glucose and lipid metabolism, in mildly hypercholesterolemic subjects. Eur J Nutr 2014, 53, 39-48. 10.1007/s00394013-0496-8

17. Shivappa, N.; Steck, S.E.; Hurley, T.G.; Hussey, J.R.; Hebert, J.R. Designing and developing a literature-derived, population-based dietary inflammatory index. Public Health Nutr 2014, 17, 1689-1696. https://doi.org/10.1017/S1368980013002115

18. Shivappa, N.; Steck, S.E.; Hussey, J.R.; Ma, Y.; Hebert, J.R. Inflammatory potential of diet and all-cause, cardiovascular, and cancer mortality in national health and nutrition examination survey iii study. Eur J Nutr 2017, 56, 683-692. 10.1007/s00394-015-1112-x

19. Kim, M.; Sohn, C. Analysis of dietary inflammatory index of metabolic syndrome in korean: Data from the health examinee cohort (2012-2014). Korean J Hum Ecol 2016, 25, 823-834. 10.5934/kjhe.2016.25.6.823

20. Garcia-Arellano, A.; Ramallal, R.; Ruiz-Canela, M.; Salas-Salvado, J.; Corella, D.; Shivappa, N.; Schroder, H.; Hebert, J.R.; Ros, E.; Gomez-Garcia, E., et al. Dietary inflammatory index and incidence of cardiovascular disease in the predimed study. Nutrients 2015, 7, 4124-4138. 10.3390/nu7064124

21. Ramallal, R.; Toledo, E.; Martinez-Gonzalez, M.A.; Hernandez-Hernandez, A.; GarciaArellano, A.; Shivappa, N.; Hebert, J.R.; Ruiz-Canela, M. Dietary inflammatory index and incidence of cardiovascular disease in the sun cohort. PLoS One 2015, 10, e0135221. 10.1371/journal.pone.0135221.

22. Neufcourt, L.; Assmann, K.E.; Fezeu, L.K.; Touvier, M.; Graffouillere, L.; Shivappa, N.; Hebert, J.R.; Wirth, M.D.; Hercberg, S.; Galan, P., et al. Prospective association between the dietary inflammatory index and cardiovascular diseases in the supplementation en vitamines et mineraux antioxydants (su.Vi.Max) cohort. J Am Heart Assoc 2016, 5, e002735. 10.1161/JAHA.115.002735

23. Tabung, F.K.; Smith-Warner, S.A.; Chavarro, J.E.; Wu, K.; Fuchs, C.S.; Hu, F.B.; Chan, A.T.; Willett, W.C.; Giovannucci, E.L. Development and validation of an empirical dietary inflammatory index. J Nutr 2016, 146, 1560-1570. 10.3945/jn.115.228718

24. Vainio, H.; Bianchini, F. Fruit and vegetables: Iarc handbooks of cancer prevention, vol. 8. Lyon, France: IARC Press: 2003.

25. Linseisen, J.; Kesse, E.; Slimani, N.; Bueno-De-Mesquita, H.B.; Ocke, M.C.; Skeie, G.; Kumle, M.; Dorronsoro Iraeta, M.; Morote Gomez, P.; Janzon, L., et al. Meat consumption in the european prospective investigation into cancer and nutrition (epic) cohorts: Results from 24hour dietary recalls. Public Health Nutr 2002, 5, 1243-1258. 10.1079/PHN2002402.

26. Grundy, S.M.; Cleeman, J.I.; Daniels, S.R.; Donato, K.A.; Eckel, R.H.; Franklin, B.A.; Gordon, D.J.; Krauss, R.M.; Savage, P.J.; Smith, S.C. Diagnosis and management of the metabolic syndrome. Circulation 2005, 112, 2735-2752. https://doi.org/10.1161/CIRCULATIONAHA.105.169404.

27. Oliveira, A.; Rodriguez-Artalejo, F.; Lopes, C. The association of fruits, vegetables, antioxidant vitamins and fibre intake with high-sensitivity c-reactive protein: Sex and body mass index interactions. Eur J Clin Nutr 2009, 63, 1345-1352. 10.1038/ejcn.2009.61

28. Chun, O.K.; Chung, S.J.; Claycombe, K.J.; Song, W.O. Serum c-reactive protein concentrations are inversely associated with dietary flavonoid intake in u.S. Adults. J Nutr 2008, 138, 753-760. $10.1093 / \mathrm{jn} / 138.4 .753$ 
29. Esmaillzadeh, A.; Azadbakht, L. Legume consumption is inversely associated with serum concentrations of adhesion molecules and inflammatory biomarkers among iranian women. $J$ Nutr 2012, 142, 334-339. https://doi.org/10.3945/jn.111.146167

30. Bonaccio, M.; Di Castelnuovo, A.; De Curtis, A.; Costanzo, S.; Bracone, F.; Persichillo, M.; Donati, M.B.; de Gaetano, G.; Iacoviello, L. Nut consumption is inversely associated with both cancer and total mortality in a mediterranean population: Prospective results from the molisani study. Br J Nutr 2015, 114, 804-811. https://doi.org/10.1017/S0007114515002378.

31. Yu, Z.; Malik, V.S.; Keum, N.; Hu, F.B.; Giovannucci, E.L.; Stampfer, M.J.; Willett, W.C.; Fuchs, C.S.; Bao, Y. Associations between nut consumption and inflammatory biomarkers. Am J Clin Nutr 2016, 104, 722-728. https://doi.org/10.3945/ajcn.116.134205

32. Rizza, S.; Muniyappa, R.; Iantorno, M.; Kim, J.A.; Chen, H.; Pullikotil, P.; Senese, N.; Tesauro, M.; Lauro, D.; Cardillo, C., et al. Citrus polyphenol hesperidin stimulates production of nitric oxide in endothelial cells while improving endothelial function and reducing inflammatory markers in patients with metabolic syndrome. J Clin Endocrinol Metab 2011, 96, E782-792. https://doi.org/10.1210/jc.2010-2879

33. Zuniga, Y.L.; Rebello, S.A.; Oi, P.L.; Zheng, H.; Lee, J.; Tai, E.S.; Van Dam, R.M. Rice and noodle consumption is associated with insulin resistance and hyperglycaemia in an asian population. Br J Nutr 2014, 111, 1118-1128. https://doi.org/10.1017/S0007114513003486

34. Yamashita, K.; Yatsuya, H.; Muramatsu, T.; Toyoshima, H.; Murohara, T.; Tamakoshi, K. Association of coffee consumption with serum adiponectin, leptin, inflammation and metabolic markers in japanese workers: A cross-sectional study. Nutr Diabetes 2012, 2, e33. 10.1038/nutd.2012.6.

35. Je, Y.; Jeong, S.; Park, T. Coffee consumption patterns in korean adults: The korean national health and nutrition examination survey (2001-2011). Asia Pac J Clin Nutr 2014, 23, 691-702. 10.6133/apjen.2014.23.4.11.37.

36. Shon, J.-K. The Effect of Cognition at Regional Area on Image, Attitude \& Intention of Behavior - Focus on Korea food consumer Behavior -. JFM 2011, 14, 321-336.

37. Kim, W.-Y.; Kim, J.-E.; Choi, Y.-J.; Huh, K.-B. Nutritional risk and metabolic syndrome in korean type 2 diabetes mellitus. Asia Pac J Clin Nutr 2008, 17, 47-51.

38. Song, S.J.; Lee, J.E.; Paik, H.-Y.; Park, M.S.; Song, Y.J. Dietary patterns based on carbohydrate nutrition are associated with the risk for diabetes and dyslipidemia. Nutr Res Pract 2012, 6, 349356. https://doi.org/10.4162/nrp.2012.6.4.349.

39. Na W; Kim M; Park S; Lee M; Sohn C. Development and validation of Korean inflammtory index(K-DII) for metabolic disease patients :by using the Health Examinee cohort (2012-2014). Korean J Hum Ecol 2017, 26, 369-381. 10.5934/kjhe.2017.26.4.369

40. Danesh, J.; Wheeler, J.G.; Hirschfield, G.M.; Eda, S.; Eiriksdottir, G.; Rumley, A.; Lowe, G.D.; Pepys, M.B.; Gudnason, V. C-reactive protein and other circulating markers of inflammation in the prediction of coronary heart disease. $N$ Engl J Med 2004, 350, 1387-1397. doi: 10.1056/NEJMoa03280441

41. Ghayour-Mobarhan, M.; Yaghootkar, H.; Lanham-New, S.A.; Lamb, D.J.; Ferns, G.A. Association between serum crp concentrations with dietary intake in healthy and dyslipidaemic patients. Asia Pac J Clin Nutr 2007, 16, 262-268. 10.6133/apjen.2007.16.09

42. Kim, M.; Kim, J.; Bae, W.; Kim, S.; Lee, Y.; Na, W.; Sohn, C. Relationship between nutrients intakes, dietary quality, and serum concentrations of inflammatory markers in metabolic syndrome patients. Korean J Community Nutr 2011, 16, 51-61. https://doi.org/10.5720/kjen.2011.16.1.51.

43. Ridker, P.M.; Buring, J.E.; Cook, N.R.; Rifai, N. C-reactive protein, the metabolic syndrome, and risk of incident cardiovascular events: An 8-year follow-up of 14719 initially healthy american $\quad$ women. $\quad$ 2003, 391-397. https://doi.org/10.1161/01.CIR.0000055014.62083.05. 
447

448

449

450

451

452

453

454

455

456

457
44. Santos, A.C.; Lopes, C.; Guimaraes, J.T.; Barros, H. Central obesity as a major determinant of increased high-sensitivity c-reactive protein in metabolic syndrome. Int J Obes (Lond) 2005, 29, 1452-1456. 10.1038/sj.ijo.0803035.

45. Indulekha, K.; Surendar, J.; Mohan, V. High sensitivity c-reactive protein, tumor necrosis factor- $\alpha$, interleukin-6, and vascular cell adhesion molecule-1 levels in asian indians with metabolic syndrome and insulin resistance (cures-105). J Diabetes Sci Technol 2011, 5, 982-988. $10.1177 / 193229681100500421$

46. Vu, J.D.; Vu, J.B.; Pio, J.R.; Malik, S.; Franklin, S.S.; Chen, R.S.; Wong, N.D. Impact of c-reactive protein on the likelihood of peripheral arterial disease in united states adults with the metabolic syndrome, diabetes mellitus, and preexisting cardiovascular disease. Am J Cardiol 2005, 96, 655-658. 10.1016/j.amjcard.2005.04.038 